\section{Merits of Chinese Prescription Kangen-karyu for Patients with Diabetic Nephropathy}

\author{
Takako Yokozawa ${ }^{1 *}$, Kazuyuki Hiratani ${ }^{2}$, Masahiro Shoji ${ }^{3}$, \\ Makoto Osanai ${ }^{4}$, Liye Zhang ${ }^{5}$ and Chan Hum Park
}

${ }^{1}$ Graduate School of Science and Engineering for Research, University of Toyama, Toyama, Japan

${ }^{2}$ Shinseikai Toyama Hospital, Toyama, Japan

${ }^{3}$ Pharmacy of Kaikido, Yokohama, Japan

${ }^{4}$ Herbal Pharmacy of Takasaki, Gunma, Japan

${ }^{5}$ /skra Industry Co., Ltd., Tokyo, Japan

${ }^{6}$ Department of Medicinal Crop Research, National Institute of Horticultural and Herbal Science, Rural Development Administration, Eumseong, Republic of Korea

\begin{abstract}
Diabetic nephropathy is a leading cause of end-stage renal disease worldwide. The mainstay of diabetic nephropathy has been the management of hyperglycemia, blood pressure and proteinuria using hypoglycemic agents, angiotensin-converting enzyme inhibitors and angiotensin receptor blockers. The application of traditional Chinese medicine to diabetic nephropathy has received increasing attention due to its wide availability, weak side-effects and proven therapeutic mechanisms and benefits. In this paper, we report the case of patients with diabetic nephropathy, stage 2 or 3 . Kangen-karyu extract ( $7.5 \mathrm{~g} /$ day) was administered three times per day for 6 months. The estimated glomerular filtration rate was increased at the 6-month follow-up. The serum creatinine level decreased following administration. At that time, somatic and subjective symptoms had partially disappeared. Here, we present evidence that Kangen-karyu exerts a renoprotective effect against the development of diabetic nephropathy.
\end{abstract}

Keywords: Case report; Diabetic nephropathy; Kangen-karyu; Traditional Chinese medicine

*Corresponding author: Takako Yokozawa, Graduate School of Science and Engineering for Research, University of Toyama, Toyama 930-8555, Japan, E-mail: yokozawa@inm.u-toyama.ac.jp

Citation: Yokozawa T, Hiratani K, Shoji M, Osanai M, Zhang L, et al. (2020) Merits of Chinese Prescription Kangen-karyu for Patients with Diabetic $\mathrm{Ne}$ phropathy. J Altern Complement Integr Med 6: 104.

Received: May 26, 2020; Accepted: May 29, 2020; Published: May 30, 2020

Copyright: ( 2020 Yokozawa T, et al. This is an open-access article distributed under the terms of the Creative Commons Attribution License, which permits unrestricted use, distribution, and reproduction in any medium, provided the original author and source are credited.

\section{Background}

Diabetic nephropathy is among the main causes of end-stage renal disease [1]. Multiple factors such as metabolic and hemodynamic alterations, oxidative stress, activation of the renin-angiotensin system, and inflammation may interdepend on various levels, causing progressive nephropathy [2]. A large number of novel treatment options has arisen from experimental studies based on the pathogenic factors of diabetic nephropathy, including intensive glycemic control, precise blood pressure control, renin-angiotensin-aldosterone system blockade, lifestyle modifications such as exercise and dietary restrictions, and numerous novel agents, but the rate of end-stage renal disease due to diabetic nephropathy still remains high in spite of the widespread application of numerous therapeutic approaches focusing on management of the factors mentioned above [3-6]. Therefore, interventions that could effectively delay the progression of diabetic nephropathy are urgently required.

\section{Kangen-karyu}

Traditional Chinese prescriptions have received much attention as potential sources of novel therapeutic agents due to their multiple beneficial effects and absence of toxic and/or side effects [7]. Kangen-karyu (Guan-Yuan-Ke-Li in Chinese), one of our major interests among traditional Chinese medicine agents, has been developed in Japan by the modification of herbal constituents of Kan-shin No. 2 (Guan-xin No.2 in Chinese) [8]. Kan-shin No. 2 was originally created following traditional Chinese medicine practice to cure blood stagnation, and it has been used to treat thrombosis, myocardial infarction and cerebral infarction in China [9]. Kangen-karyu consists of six herbs (Salviae Miltiorrhizae Radix, Cnidii Rhizoma, Paeoniae Radix, Carthami Flos, Aucklandiae Radix and Cyperi Rhizoma) (Table 1), and has been clinically used as a treatment for cardiovascular diseases such as angina pectoris and cerebrovascular diseases. Many studies demonstrated that Kangen-karyu exhibits favorable biological activity such as anti-aging effects, platelet aggregation inhibition, hypertension suppression, anti-dyslipidemia, aiding the recovery of learning and memory impairment induced by senescence, neuroprotection, and an anti-dementia effect in animal experiments [10-17]. Although studies have proposed the pharmacological functions of Kangen-karyu to treat various diseases, we previously reported evidence supporting its preventive and/or therapeutic potential against diabetes-induced renal damage using $d b / d b$ mice, a type 2 diabetic animal model [18-20]. The results of our previous study provide important evidence that Kangen-karyu exerts a renoprotective effect against the development of diabetic nephropathy. We also provide evidence supporting the use of Kangen-karyu as a therapeutic agent in a patient with diabetic nephropathy in the early stage [21]. On the basis of these findings, we administered Kangen-karyu to diabetic nephropathy patients, stage 2 or 3 , and report its therapeutic usefulness. 
Citation: Yokozawa T, Hiratani K, Shoji M, Osanai M, Zhang L, et al. (2020) Merits of Chinese Prescription Kangen-karyu for Patients with Diabetic Nephropathy. J Altern Complement Integr Med 6: 104.

\begin{tabular}{|c|c|c|}
\hline Common name & Botanical name & Family name \\
\hline Salviae Miltiorrhizae Radix & Salvia miltiorrhiza BUNGE & Labiatae \\
\hline Cnidii Rhizoma & Cnidium officinale MAKINO & Umbelliferae \\
\hline Paeoniae Radix & Paeonia lactiflora PALLAS & Paeoniaceae \\
\hline Carthami Flos & Carthamus tinctorius $\mathrm{L}$. & Compositae \\
\hline Aucklandiae Radix & Aucklandia lappa DCNE. & Compositae \\
\hline Cyperi Rhizoma & Cyperus rotundus $\mathrm{L}$. & Cyperaceae \\
\hline
\end{tabular}

\section{Clinical studies}

\section{Study population}

The study cohort was previously diagnosed with diabetic nephropathy at Shinseikai Toyama Hospital. Both sexes ( 3 men and 2 women; 54-73 years, $64.0 \pm 3.8$ years) and two stages of diabetic nephropathy (3, stage 2 ; and 2, stage 3 ) were represented. The patients continued to receive existing treatments: hypoglycemic agents (metformin: 750 $\mathrm{mg} /$ day, ipragliflozin: $50 \mathrm{mg} /$ day), an antihypertensive agent (termisartan: $20 \mathrm{mg} /$ day), antilipidemic agent (atrovastatin: $5 \mathrm{mg} /$ day), and antacid-laxative (magnesium oxide: $990 \mathrm{mg} /$ day). In addition, Kangen-karyu extract $(7.5 \mathrm{~g} /$ day $)$ was administered three times a day for 6 months. During the administration of Kangen-karyu extract, regular tests were performed to assess its effect on diabetic nephropathy. At that time, a medical interview including questions on the somatic and subjective symptoms was conducted during the study.

\section{Laboratory data and physical characteristics on adminis- tration of Kangen-karyu for 6 months}

From samples obtained at the first timepoint, hemoglobin A1c (HbA1c) was $7.52 \%$, showing poorly controlled blood glucose. The estimated glomerular filtration rate (eGFR) was $79.2 \mathrm{~mL} / \mathrm{min} / 1.73$ $\mathrm{m}^{2}$, and this corresponded to a serum creatinine $(\mathrm{Cr})$ level of 0.71 $\mathrm{mg} / \mathrm{dL}$. The urinary albumin and protein levels were 56.1 and 425 $\mathrm{mg} / \mathrm{g} \mathrm{Cr}$, respectively, indicating stage 2 to 3 diabetic nephropathy. After the administration of Kangen-karyu extract for 6 months, eGFR was subsequently increased from 79.2 to $88.2 \mathrm{~mL} / \mathrm{min} / 1.73 \mathrm{~m}^{2}$ at the 6-month follow-up, and serum $\mathrm{Cr}$ was slightly decreased compared with the first timepoint. The urinary albumin level increased from 56.1 to $71.0 \mathrm{mg} / \mathrm{g}$ Cr. Urinary protein excretion also increased to 506 $\mathrm{mg} / \mathrm{g}$ Cr. There was, however, no significant change in the HbAlc on the administration of Kangen-karyu extract.

Moreover, to identify the therapeutic usefulness of Kangen-karyu extract to improve the renal function of diabetic nephropathy patients, we investigated the eGFR and serum Cr levels in patients from the 6th month prior to Kangen-karyu extract administration. As shown in Table 2, the eGFR level of diabetic nephropathy patients was gradually decreased as time progressed until 6 months, indicating renal function decline. On the other hand, the administration of Kangen-karyu was increased from 79.2 to $80.7 \mathrm{~mL} / \mathrm{min} / 1.73 \mathrm{~m}^{2}$ at 1 month, 81.9 $\mathrm{mL} / \mathrm{min} / 1.73 \mathrm{~m}^{2}$ at 3 months, and $88.2 \mathrm{~mL} / \mathrm{min} / 1.73 \mathrm{~m}^{2}$ at 6 months. When the rate of variability in eGFR was calculated using the formula shown in Table 3, its value was significantly recovered by Kangen-karyu administration. Additionally, a slight increase of serum $\mathrm{Cr}$ that progressed in diabetic nephropathy patients was progressively decreased by the administration of Kangen-karyu at the 6-month follow-up, as shown in Table 2. The rate of variability in serum $\mathrm{Cr}$ was significantly decreased by Kangen-karyu (Table 3). GFR is the most accurate index for assessing overall kidney function and important tool for making diagnostic decisions in clinical practice [22], but the method is not applicable to daily practice because it is time consuming, labor intensive, and expensive. Kidney function usually is assessed from serum $\mathrm{Cr}$ concentration alone. However, serum $\mathrm{Cr}$ is affected by $\mathrm{Cr}$ generation, including muscle mass and dietary intake, in addition to GFR [23]. Therefore, we used the eGFR on the equation proposed by the Japanese Society of Nephrology [24].

\begin{tabular}{|c|c|c|c|c|c|c|c|}
\hline \multicolumn{7}{|c|}{ Kangen-karyu administration } \\
\hline & $-6 \mathrm{M}$ & $-3 \mathrm{M}$ & $-1 \mathrm{M}$ & $0 \mathrm{M}$ & $1 \mathrm{M}$ & $3 \mathrm{M}$ & $6 \mathrm{M}$ \\
\hline $\mathrm{eGFR}$ & 84.6 & 80.3 & 79.2 & 79.2 & 80.7 & 81.9 & 88.2 \\
\hline$\left(\mathrm{mL} / \mathrm{min} / 1.73 \mathrm{~m}^{2}\right)$ & \pm 9.4 & \pm 7.9 & \pm 5.8 & \pm 8.8 & \pm 8.3 & \pm 7.9 & \pm 9.0 \\
\hline $\mathrm{Serum} \mathrm{Cr}$ & 0.67 & 0.70 & 0.70 & 0.71 & 0.70 & 0.68 & 0.64 \\
\hline$(\mathrm{mg} / \mathrm{dL})$ & \pm 0.14 & \pm 0.06 & \pm 0.05 & \pm 0.07 & \pm 0.07 & \pm 0.05 & \pm 0.09 \\
\hline
\end{tabular}

Table 2: Changes in eGFR and serum $\mathrm{Cr}$ before and after Kangen-karyu administration.

$M$, months. Values are expressed as the mean \pm S.E. of 5 patients.

\begin{tabular}{|c|c|c|}
\hline & $\begin{array}{c}\text { (At the start of administration } \mathbf{~ 6 ~} \\
\text { months before administration) } / \mathbf{6}\end{array}$ & $\begin{array}{l}\text { (At the start of administration }-\mathbf{6} \\
\text { months after administration) / } 6\end{array}$ \\
\hline eGFR & $-0.894 \pm 0.288$ & $1.491 \pm 0.406^{*}$ \\
\hline Serum Cr & $0.007 \pm 0.002$ & $-0.012 \pm 0.003^{\circ}$ \\
\hline
\end{tabular}

Table 3: Rate of variability in eGFR and serum Cr before and after Kangen-karyu administration.

Significance: ${ }^{*} \mathrm{p}<0.01$ vs. (at the start of administration -6 months before administration) $/ 6$ values.

Regarding the physical characteristics, there was no significant change in the parameters such as body mass index (BMI), soft lean mass (SLM), body fat mass (BFM), visceral fat area (VFA), or percent body fat (PBF) on the administration of Kangen-karyu extract. At the 6-month follow-up of patients, somatic and subjective symptoms such as stiff shoulder, headache, coldness of the limbs, and fatigability had disappeared. The score using the questionnaire had decreased from 38.6 to 27.2 at follow-up, being a significantly lower $(30 \%)$ score.

\section{Discussion}

The utilization of traditional Chinese medicine to treat patients with diabetic nephropathy has received increasing attention due to its wide availability, weak side-effects, and proven therapeutic mechanisms and benefits. In the present patients, there was an improvement in diabetic nephropathy following the administration of Kangen-karyu for 6 months. Because of the short follow-up period, the effect of the long-term administration of Kangen-karyu on progressive nephropathy remains unknown. However, eGFR was subsequently increased 
Citation: Yokozawa T, Hiratani K, Shoji M, Osanai M, Zhang L, et al. (2020) Merits of Chinese Prescription Kangen-karyu for Patients with Diabetic Nephropathy. J Altern Complement Integr Med 6: 104.

from 79.2 to $88.2 \mathrm{~mL} / \mathrm{min} / 1.73 \mathrm{~m}^{2}$ at the 6 -month follow-up. The serum $\mathrm{Cr}$ level decreased from 0.71 to $0.64 \mathrm{mg} / \mathrm{dL}$. In addition, the score using the questionnaire was significantly decreased during the follow-up. We present the therapeutic option using Kangen-karyu to treat renal disease patients with diabetic nephropathy. Interesting findings were also obtained with regard to eGFR: the level of eGFR gradually decreased at $6,3,1$, and 0 months prior to Kangen-karyu extract administration. The administration of Kangen-karyu for 6 months increased this level, and the rate of variability in eGFR was significantly recovered. There were, however, no improvements in the urinary albumin or protein levels on the administration of Kangen-karyu.

Albuminuria is characterized clinically as an early predictor of the progression of diabetic nephropathy [25]. Proteinuria is a universal finding in patients with progressive renal disease, and considered a measure of the severity and determinant of diabetic renal disease progression [26], whereas eGFR is estimated using endogenous plasma or serum filtration markers, most commonly $\mathrm{Cr}[27,28]$. We showed that $\mathrm{Cr}$ reacts with hydroxyl radicals to quantitatively and non-enzymatically produce 5-hydroxycreatinine, which partially decomposes to methylguanidine, a stronger uremic toxin. These reactions have been reported to occur not only in vitro but also in vivo [29]. Moreover, we suggested that the efficacy of Kangen-karyu on diabetic nephropathy in type 2 diabetic $d b / d b$ mice was dependent on several oxidative stress-related parameters and exerted a renoprotective effect [18-20]. Thus, Kangen-karyu may function as an ameliorator of oxidative stress and show beneficial effects for diabetic nephropathy patients. In addition, the score using the questionnaire was decreased during the follow-up. Herein, we present the therapeutic option of Kangen-karyu to treat patients in the early phase of diabetic nephropathy.

\section{Conclusion}

We report evidence supporting the use of Kangen-karyu as an adjunctive therapy for patients with diabetic nephropathy corresponding to stage 2 or 3 . Kangen-karyu exhibits good efficacy in the treatment of patients with diabetic nephropathy.

\section{References}

1. Liyanage T, Ninomiya T, Jha V, Neal B, Patrice HM, et al. (2015) Worldwide access to treatment for end-stage kidney disease: a systematic review. Lancet 385: 1975-1982.

2. Duran-Salgado MB, Rubio-Guerra AF (2014) Diabetic nephropathy and inflammation. World J Diabetes 5: 393-398.

3. Lim A (2014) Diabetic nephropathy - complications and treatment. Int J Nephrol Renovasc Dis 7: 361-381.

4. Heerspink HJ, de Zeeuw D (2011) The kidney in type 2 diabetes therapy. Rev Diabet Stud 8: 392-402.

5. Fried LF, Emanuele N, Zhang JH, Brophy M, Conner TA, et al. (2013) Combined angiotensin inhibition for the treatment of diabetic nephropathy. N Engl J Med 369: 1892-1903.

6. Yamout H, Lazich I, Bakris GL (2014) Blood pressure, hypertension, RAAS blockade, and drug therapy in diabetic kidney disease. Adv Chronic Kidney Dis 21: 281-286.

7. Winslow LC, Kroll DJ (1998) Herbs as medicine. Arch Intern Med 158: 2192-2199.
8. Makino T, Wakushima H, Okamoto T, Okukubo Y, Deguchi Y, et al. (2003) Pharmacokinetic and pharmacological interactions between ticlopidine hydrochloride and Kangen-karyu - Chinese traditional herbal medicine. Phytother Res 17: 1021-1024.

9. Qin F, Huang X (2009) Guanxin II for the management of coronary heart disease. Chin J Integr Med 15: 472-476.

10. Takahashi M, Sugaya K, Kubota K (1992) Kangenkaryu prevents the decrease of cholinergic markers following the nucleus basalis magnocellularis lesion. Jpn J Pharmacol 60: 307-310.

11. Gao M, Ikeda K, Noguchi T, Mori K, Yamori Y (2001) Studies on preventive effect of 'Kangenkaryu', Chinese herbal medicine, on stroke in SHRSP. J Trad Med 18: 245-250.

12. Makino T, Wakushima H, Okamoto T, Okukubo Y, Saito K, et al. (2002) Effects of Kangen-karyu on coagulation system and platelet aggregation in mice. Biol Pharm Bull 25: 523-525.

13. Yokozawa T, Cho EJ, Okamoto T, Sei Y (2006) Effects of Chinese prescription Kangen-karyu and its crude drug Tanjin on ageing process in rats. J Pharm Pharmacol 58: 1591-1599.

14. Pu F, Kaneko T, Enoki M, Irie K, Okamoto T, et al. (2010) Ameliorating effects of Kangen-karyu on neuronal damage in rats subjected to repeated cerebral ischemia. J Nat Med 64: 167-174.

15. Yamabe N, Kim HY, Kang KS, Zhao Q, Matsumoto K, et al. (2010) Effect of Chinese prescription Kangen-karyu on lipid metabolism in type 2 diabetic $d b / d b$ mice. J Ethnopharmacol 129: 299-305.

16. Zhao Q, Yokozawa T, Yamabe N, Tsuneyama K, Li X, et al. (2010) Kangen-karyu improves memory deficit caused by aging through normalization of neuro-plasticity-related signaling system and VEGF system in the brain. J Ethnopharmacol 131: 377-385.

17. Noh JS, Park CH, Kim HY, Zhao Q, Yamabe N, et al. (2011) Chinese prescription Kangen-karyu prevents dyslipidaemia and oxidative stress in mouse model of type 2 diabetes. J Pharm Pharmacol 63: 111-119.

18. Yokozawa T, Park CH, Matsumoto K (2017) Scientific evidence for therapeutic effects of Chinese prescription Kangen-karyu from pre-clinical animal experiments. Drug Discov Ther 11: 6-14.

19. Park CH, Noh JS, Yamabe N, Okamoto T, Kang KS, et al. (2010) Renoprotective effect of Kangen-karyu on the development of diabetic nephropathy in type 2 diabetic $d b / d b$ mice. J Trad Med 27: 192-203.

20. Okamoto T, Park CH, Noh JS, Toriizuka K, Sei Y, et al. (2011) Hepato-/ reno-protective activity of Chinese prescription Kangen-karyu through inhibition of AGE formation and fibrosis-related protein expression in type 2 diabetes. J Pharm Pharmacol 63: 952-959.

21. Hiratani K, Shoji M, Osanai M, Zhang L, Park CH, et al. (2019) Treatment of patient with diabetic nephropathy using Chinese prescription Kangen-karyu. Arch Clin Med Case Rep 3: 261-268.

22. Stevens LA, Coresh J, Greene T, Levey AS (2006) Assessing kidney function - measured and estimated glomerular filtration rate. N Engl J Med 354: $2473-2483$.

23. Myers GL, Miller WG, Coresh J, Fleming J, Greenberg N, et al. (2006) Recommendations for improving serum creatinine measurement: a report from the laboratory working group of the National Kidney Disease Education Program. Clin Chem 52: 5-18.

24. Matsuo S, Imai E, Horio M, Yasuda Y, Tomita K, et al. (2009) Revised equations for estimated GFR from serum creatinine in Japan. Am J Kidney Dis 53: $982-992$.

25. Keane WF, Brenner BM, de Zeeuw D, Grunfeld JP, McGill J, et al. (2003) The risk of developing end-stage renal disease in patients with type 2 diabetes and nephropathy: the RENAAL study. Kidney Int 63: 1499-1507. 
Citation: Yokozawa T, Hiratani K, Shoji M, Osanai M, Zhang L, et al. (2020) Merits of Chinese Prescription Kangen-karyu for Patients with Diabetic Nephropathy. J Altern Complement Integr Med 6: 104.

- Page 4 of 4 -

26. Williams ME (2005) Diabetic nephropathy: the proteinuria hypothesis. Am J Nephrol 25: 77-94.

27. Levey AS, Bosch JP, Lewis JB, Greene T, Rogers N, et al. (1999) A more accurate method to estimate glomerular filtration rate from serum creatinine: a new prediction equation. Modification of diet in renal disease study group. Ann Intern Med 130: 461-470.
28. Levey AS, Inker LA, Coresh J (2014) GFR estimation: from physiology to public health. Am J Kidney Dis 63: 820-834.

29. Ienaga K, Yokozawa T (2011) Creatinine and HMH (5-hydroxy-1-methylhydantoin, NZ-419) as intrinsic hydroxyl radical scavengers. Drug Discov Ther 5: 162-175. 